\title{
Hubungan antara Pengetahuan dan Sikap Keluarga dengan Kemampuan dalam Pelaksanaan Oral Hygiene di Ruang Musdalifah RSI Siti Khadijah Palembang
}

\author{
Lenny Astuti ${ }^{1}$, Ahmad Khoiri ${ }^{2}$ \\ ${ }^{1,2}$ Program Studi Ners, STIK Siti Khadijah Palembang \\ Email: lenny_astuti88@yahoo.com
}

\begin{abstract}
Relationship between Knowledge, Family Attitudes, and Ability in Oral Hygiene Implementation at Musdalifah Room Siti Khadijah Islamic Hospital Palembang. Patients with consciousness disorder may experience physical mobility and swallowing food disorder through the mouth so it can be one cause of inflammation of the mucous membranes of the mouth. Oral hygiene in oral and dental health is very important. The aim of this study was to determine the relationship between knowledge, family attitudes, and ability in oral hygiene implementation at musdalifah room Siti Khadijah Islamic Hospital Palembang in 2017. This study used quantitative with the cross sectional design. The population of this study was all family of patients that treated at Musdalifah Room Siti Khadijah Islamic Hospital Palembang in 2017. The number of samples was 91 respondents. Analysis the data used by univariate and bivariate. The result is Most of them have good knowledge were 51 respondents $(56.0 \%)$, most have positive attitude were 49 respondents $(53.8 \%)$ and most have good oral hygiene implementation ability were 58 respondents $(63,7 \%)$. Based on the analysis using chi-square test, there was a correlation between knowledge with ability in oral hygiene implementation $(\rho=0,027)$ and there was a relationship of attitude with ability in oral hygiene implementation $(\rho=0,016)$. Finally, it is expected that this study could be a reference to improve the quality of professionalism in providing services to critical patients to be able to improve the ability of oral hygiene implementation.
\end{abstract}

Keywords: Knowledge, Attitude, Oral hygiene implementation

\begin{abstract}
Abstrak: Hubungan antara Pengetahuan dan Sikap Keluarga dengan Kemampuan dalam Pelaksanaan Oral hygiene di Ruang Musdalifah Rumah Sakit Islam Siti Khadijah Palembang. Pada penderita yang mengalami gangguan penurunan kesadaran dapat mengalami imobilitas fisik dan gangguan menelan makanan lewat mulut sehingga dapat menjadi salah satu penyebab terjadinya peradangan selaput lendir mulut. Kebersihan mulut dalam kesehatan gigi dan mulut sangatlah penting. Penelitian ini bertujuan untuk mengetahui hubungan antara pengetahuan dan sikap keluarga dengan kemampuan dalam pelaksanaan oral hygiene di Ruang Musdalifah Rumah Sakit Islam Siti Khadijah Palembang Tahun 2017. Penelitian ini menggunakan penelitian kuantitatif dengan pendekatan desain cross sectional. Populasi penelitian ini adalah semua keluarga pasien yang dirawat di Ruang Musdalifah Rumah Sakit Islam Siti Khadijah Palembang Tahun 2017, dengan jumlah sampel yaitu 91 responden. Teknik analisa data dilakukan secara univariat dan bivariat. Hasil penelitian didapatkan bahwa sebagian besar memiliki pengetahuan baik sebanyak 51 responden $(56,0 \%)$, sebagian besar memiliki sikap positif sebanyak 49 responden $(53,8 \%)$ dan sebagian besar memiliki kemampuan pelaksanaan oral hygiene baik sebanyak 58 responden $(63,7 \%)$. Berdasarkan analisis menggunakan uji chi-square, didapatkan ada hubungan pengetahuan dengan kemampuan dalam pelaksanaan oral hygiene $(\rho=0,027)$ dan ada hubungan sikap dengan kemampuan dalam pelaksanaan oral hygiene $(\rho=0,016)$. Adapun saran yang diberikan diharapkan dapat menjadi acuan untuk meningkatkan kualitas profesionalisme dalam memberikan pelayanan kepada pasien kritis untuk dapat meningkatkan kemampuan pelaksanaan oral hygiene.
\end{abstract}

Kata kunci: Pengetahuan, Sikap, Pelaksanaan Oral Hygiene

Oral hygiene merupakan salah satu tindakan yang diperlukan untuk menjaga agar mulut terhindar dari infeksi, membersihkan dan menyegarkan mulut (Clark dalam Ghofar, 2015).
Oral hygiene dalam kesehatan gigi dan mulut sangatlah penting, beberapa masalah mulut dan gigi bisa terjadi karena kurangnya menjaga kebersihan mulut dan gigi. Kesadaran menjaga oral hygiene sangat perlu dan merupakan obat 
pencegah terjadinya masalah gigi dan mulut yang paling manjur (Perry dan Potter, 2005).

Pada penderita yang mengalami gangguan penurunan kesadaran dapat mengalami imobilitas fisik, gangguan menelan makanan lewat mulut sehingga dapat menjadi salah satu penyebab terjadinyaperadangan selaput lendir mulut. Penderita yang mengalami gangguan menelan makanan diberikan melalui selang, sehingga ludah jarang mengalami pergantian yang memudahkan terbentuknya kolonimikroflora oral komensal, apabila dibiarkankeadaan tersebut dapat mendorong terjadinya infeksi rongga mulut (Marni, 2013).

Kebersihan mulut dalam kesehatan gigi dan mulut sangatlah penting. Beberapa masalah mulut dan gigi bisa terjadi karena kurang menjaga kebersihan mulut dan gigi. Kebersihan mulut sangat penting sebab terkait dengan perawatan kesehatan tubuh secara keseluruhan terutama pada klien yang mengalami penurunan kesadaran. Perawatan rongga mulut pada klien penurunan kesadaran penting karena mikroorganisme yang berasal dari rongga mulut dapat menyebabkan infeksi atau penyakit di bagian tubuh yang lain, seperti penyakit jantung (Ahmad, 2014).

Salah satu faktor yang mempengaruhi kesehatan gigi dan mulut adalah tingkat pengetahuan, sikap dan tindakan. Pengetahuan berperan penting dalam perkembangan perilaku seseorang. Pengetahuan yang baik mengenai kebersihan mulut sangat penting untuk mencegah penyakit gigi dan mulut, meningkatkan daya tahan tubuh, dan memperbaiki fungsi mulut untuk memperbaiki nafsu makan (Nidyawati, dkk, 2013). Pengetahuan mengenai kesehatan gigi dan mulut diperoleh melalui proses kognitif yang kompleks.

Keluarga merupakan unsur penting yang harus dilibatkan dalam melakukan tindakan perawatan, karena keluargalah yang paling dekat. Keluarga adalah bagian dari masyarakat yang peranannya sangat penting untuk membentuk kebudayaan yang sehat. Dari keluarga inilah pendidikan kepada individu dimulai dan dari keluarga inilah akan tercipta tatanan masyarakat yang baik, sehingga untuk membangun suatu kebudayaan maka seyogyanya dimulai dari keluarga.

Berdasarkan hal tersebut di atas, maka peneliti tertarik untuk melakukan penelitian tentang hubungan antara pengetahuan dan sikap keluarga dengan kemampuan dalam pelaksanaan oral hygiene di Ruang Musdalifah Rumah Sakit Islam Siti Khadijah Palembang Tahun 2017.
Berdasarkan uraian di atas tujuan dalam penelitian ini adalah diketahuinya hubungan antara pengetahuan dan sikap keluarga dengan kemampuan dalam pelaksanaan oral hygiene di Ruang Musdalifah RSI Siti Khadijah Palembang tahun 2017.

\section{METODE}

Penelitian ini menggunakan desain penelitian kuantitatif survey analitik dengan pendekatan desain cross sectional. Populasi dalam penelitian ini adalah semua keluarga pasien yang dirawat di Ruang Musdalifah Rumah Sakit Islam Siti Khadijah Palembang periode bulan Januari-Mei Tahun 2017, yang berjumlah 976 orang.

Sampel yang digunakan adalah keluarga pasien yang dirawat di Ruang Musdalifah Rumah Sakit Islam Siti Khadijah Palembang Tahun 2017. Teknik pengambilan sampel dalam penelitian ini menggunakan teknik accidental sampling.

Dalam penelitian ini menggunakan data primer dan data sekunder. Data primer yang diperlukan dalam penelitian ini meliputi: data pengetahuan, sikap dan kemampuan keluarga dalam pelaksanaan oral hygiene yang diperoleh melalui pengukuran langsung dengan responden dengan menggunakan lembar kuesioner. Data sekunder diperoleh dari Rumah Sakit Islam Siti Khadijah Palembang, yaitu data jumlah pasien yang dirawat Ruang Musdalifah Rumah Sakit Islam Siti Khadijah Palembang.

\section{HASIL}

\section{A. ANALISIS UNIVARIAT}

Tabel 1. Distribusi Frekuensi Responden Menurut Pengetahuan

\begin{tabular}{lcc}
\hline \multicolumn{1}{c}{ Pengetahuan } & Jumlah & $\boldsymbol{\%}$ \\
\hline Baik & 51 & 56,0 \\
\hline Kurang & 40 & 44,0 \\
\hline Total & 91 & 100 \\
\hline
\end{tabular}

Berdasarkan tabel 1, dapat diketahui bahwa dari 91 responden, yang memiliki pengetahuan baik sebanyak 51 responden (56,0\%), lebih banyak jika dibandingkan dengan reponden yang memiliki pengetahuan kurang yaitu sebanyak 40 responden $(44,0 \%)$. 
Tabel 2. Distribusi Frekuensi Responden Menurut Sikap

\begin{tabular}{lcc}
\multicolumn{1}{c}{ Sikap } & Jumlah & \% \\
\hline Positif & 49 & 53,8 \\
\hline Negatif & 42 & 46,2 \\
\hline Total & 91 & 100 \\
\hline
\end{tabular}

Berdasarkan tabel 2, dapat diketahui bahwa dari 91 responden, yang memiliki sikap positif sebanyak 49 responden $(53,8 \%)$, lebih banyak jika dibandingkan dengan reponden yang memiliki sikap negatif yaitu sebanyak 42 responden $(46,2 \%)$.

Tabel 3. Distribusi Frekuensi Responden Menurut Kemampuan Keluarga dalam Pelaksanaan Oral Hygiene

\begin{tabular}{lrr}
\hline $\begin{array}{c}\text { Kemampuan Keluarga } \\
\text { dalam Pelaksanaan } \\
\text { Oral Hygiene }\end{array}$ & Jumlah & $\%$ \\
\hline Baik & 58 & 63,7 \\
\hline Kurang & 33 & 36,3 \\
\hline Total & 91 & 100 \\
\hline
\end{tabular}

Berdasarkan tabel 3, dapat diketahui bahwa dari 91 responden, yang memiliki kemampuan pelaksanaan oral hygiene baik sebanyak 58 responden $(63,7 \%)$, lebih banyak jika dibandingkan dengan reponden yang memiliki kemampuan pelaksanaan oral hygiene kurang baik yaitu sebanyak 33 responden $(36,3 \%)$.

\section{B. ANALISIS BIVARIAT}

Tabel 4. Hubungan antara Pengetahuan dengan Kemampuan Dalam Pelaksanaan Oral hygiene

\begin{tabular}{|c|c|c|c|c|c|c|}
\hline \multirow[t]{3}{*}{ Pengetahuan } & \multicolumn{4}{|c|}{$\begin{array}{c}\text { Kemampuan dalam } \\
\text { Pelaksanaan Oral } \\
\text { Hygiene }\end{array}$} & \multirow{2}{*}{\multicolumn{2}{|c|}{ Jumlah }} \\
\hline & \multicolumn{2}{|c|}{ Baik } & \multicolumn{2}{|c|}{ Kurang } & & \\
\hline & $\mathbf{n}$ & $\%$ & $\mathbf{n}$ & $\%$ & n & $\%$ \\
\hline Baik & 38 & 74,5 & 13 & 25,5 & 51 & 100 \\
\hline Kurang & 20 & 50,0 & 20 & 50,0 & 40 & 100 \\
\hline Jumlah & 58 & 63,7 & 33 & 36,3 & 91 & 100 \\
\hline$p$-value $=0,028$ & \multicolumn{6}{|c|}{$\mathrm{OR}=2923$} \\
\hline
\end{tabular}

Pada tabel 4 didapatkan dari 58 responden, responden yang memiliki kemampuan oral hygiene baik dan memiliki pengetahuan baik sebanyak 38 orang $(74,5 \%)$, lebih banyak jika dibandingkan dengan responden yang memiliki kemampuan oral hygiene kurang baik dan memiliki pengetahuan baik yaitu sebanyak 13 orang $(25,5 \%)$. Hasil uji statistik chi square didapatkan $\rho$-value $=0,027$ yang menunjukkan bahwa ada hubungan yang bermakna antara pengetahuan dengan kemampuan dalam pelaksanaan oral hygiene di Ruang Musdalifah Rumah Sakit Islam Siti Khadijah Palembang Tahun 2017. Hasil OR didapatkan 2,923, yang berarti responden yang memiliki pengetahuan baik mempunyai peluang 2,92 kali memiliki kemampuan oral hygiene baik.

Tabel 5. Hubungan antara Sikap Dengan Kemampuan dalam Pelaksanaan Oral Hygiene

\begin{tabular}{|c|c|c|c|c|c|c|}
\hline \multirow[t]{3}{*}{ Sikap } & \multicolumn{4}{|c|}{$\begin{array}{c}\text { Kemampuan dalam } \\
\text { Pelaksanaan Oral } \\
\text { Hygiene } \\
\end{array}$} & \multirow{2}{*}{\multicolumn{2}{|c|}{ Jumlah }} \\
\hline & \multicolumn{2}{|c|}{ Baik } & \multicolumn{2}{|c|}{ Kurang } & & \\
\hline & $\mathrm{n}$ & $\%$ & $\mathrm{n}$ & $\%$ & $\mathrm{n}$ & $\%$ \\
\hline Positif & 37 & 75,5 & 12 & 24,5 & 49 & 100 \\
\hline Negatif & 21 & 50,0 & 21 & 50,0 & 42 & 100 \\
\hline Jumlah & 58 & 63,7 & 33 & 36,3 & 91 & 100 \\
\hline \multicolumn{5}{|c|}{$p$-value $=0,021$} & 88-7 & 99) \\
\hline
\end{tabular}

Pada tabel 5 didapatkan dari 49 responden, responden yang memiliki kemampuan oral hygiene baik dan memiliki sikap positif sebanyak 37 orang (75,5\%), lebih banyak jika dibandingkan dengan responden yang memiliki kemampuan oral hygiene kurang dan memiliki sikap positif yaitu sebanyak 12 orang $(24,5 \%)$. Hasil uji statistik chi square didapatkan $\rho$ value $=0,016$ yang menunjukkan bahwa ada hubungan yang bermakna antara sikap dengan kemampuan dalam pelaksanaan oral hygiene di Ruang Musdalifah Rumah Sakit Islam Siti Khadijah Palembang Tahun 2017. Hasil OR didapatkan 3,083, yang berarti responden yang memiliki sikap positif mempunyai peluang 3,08 kali memiliki kemampuan oral hygiene baik.

\section{PEMBAHASAN}

Hubungan antara Pengetahuan dengan Kemampuan dalam Pelaksanaan Oral Hygiene

Berdasarkan hasil penelitian diketahui bahwa ada hubungan yang bermakna antara pengetahuan dengan kemampuan dalam pelaksanaan oral hygiene.

Menurut Notoatmodjo (2007), pengetahuan atau kognitif merupakan domain yang sangat penting dalam membentuk tindakan seseorang. Sebelum seseorang berperilaku, individu tersebut harus mengerti terlebih dahulu manfaat perilaku tersebut bagi dirinya atau keluarganya. Apabila seseorang dalam proses adopsi perilaku didasari oleh pengetahuan maka perilaku tersebut akan bersifat long lasting. Pengetahuan yang baik tentunya akan berdampak 
pada kemampuan perawat dalam melaksanakan oral hygiene pada pasien.

Sesorang yang mampu mengadopsi perilaku baru diharapkan juga mampu memformulasikan perilaku tersebut dalam melaksanakan tugas-tugas yang dihadapi (Ghofar, dkk, 2015). Dari hasil penelitian ini menunjukan bahwa tingkat pengetahuan yang dimiliki oleh responden cukup baik, dan sudah dapat menjalankan kemampuan pelaksanaan oral hygiene dengan cukup baik.

Peneliti berasumsi bahwa responden dalam penelitian ini sebagian besar satu rumah dengan pasien, sehingga responden dalam penelitian ini merawat langsung anggota keluarga yang sedang sakit, ini merupakan hal yang cukup bagi mereka untuk mendapatkan pengalaman bagi mereka dalam pelaksanaan oral hygiene yang baik, apalagi kader kesehatan pernah memberi penyuluhan kesehatan tentang pelaksanaan oral hygiene kepada mereka. Sehingga sebagian besar responden dalam penelitian ini dikategorikan memiliki pelaksanaan oral hygiene yang baik dikarenakan responden dalam penelitian ini memiliki pengetahuan baik mengenai oral hygiene.

\section{Hubungan antara Sikap dengan Kemampuan dalam Pelaksanaan Oral Hygiene}

Berdasarkan hasil penelitian diketahui bahwa ada hubungan yang bermakna antara sikap responden dengan kemampuan dalam pelaksanaan oral hygiene. Hal ini sejalan dengan penelitian Wulandari (2015) bahwa ada hubungan antara sikap caring perawat dengan pelaksanaan oral hygiene. Seseorang dengan pengetahuan yang baik tentu akan memberikan pelayanan yang maksimal. Begitu pula dengan sikap dari keluarga pasien. Keluarga merupakan orang terdekat yang meski tanpa pelatihan khusus pasti memiliki sikap yang cakap dalam pelaksanaan oral hygiene.

Pasien yang tidak mampu mandiri dapat menjaga kebersihan mulut jika hal tersebut dibantu dari keluarga penderita. Keluarga yang dapat melatih dan memotivasi penderita untuk melakukan aktivitas oral hygiene akan membuat pasien kembali melakukan aktifitas tanpa tergantung orang lain. Perilaku yang baik tersusun dengan berbagai aspek yang ia miliki, perilaku diaplikasikan dengan bentuk sikap seseorang. Hal ini sebagai hasil pembentukan diri seseorang yang lebih berkualitas. Sehingga bermanfaat bagi dirinya, keluarga dan masyarakat yang membutuhkan.

\section{SIMPULAN}

Berdasarkan hasil penelitian maka dapat disimpulkan bahwa ada hubungan pengetahuan dengan kemampuan dalam pelaksanaan oral hygiene di Ruang Musdalifah Rumah Sakit Islam Siti Khadijah Palembang Tahun $2017(\rho=0,027)$ dan ada hubungan sikap dengan kemampuan dalam pelaksanaan oral hygiene di Ruang Musdalifah Rumah Sakit Islam Siti Khadijah Palembang Tahun 2017 ( $\rho=0,016)$.

\section{SARAN}

Melihat hasil kesimpulan di atas, ada beberapa saran yang perlu diperhatikan dan ditindak lanjuti dan diharapkan dapat menjadi acuan untuk meningkatkan kualitas profesionalisme dalam memberikan pelayanan kepada pasien kritis untuk dapat meningkatkan kemampuan pelaksanaan oral hygiene.

\section{DAFTAR PUSTAKA}

Ahmad, 2014. Perawatan Gigi dan Mulut. Jakarta. Prestasi Pustaka.

Ghofar, A., \& Subeqi, M. I. 2015. Hubungan antara Pengetahuan dan Sikap Perawat dengan Kemampuan Teknikal Perawat dalam Pelaksanaan Oral Hygiene pada Penderita Stroke. Eduhealth, 5(1).

Marni, 2013. Faktor-faktor yang Mempengaruhi Perawat dalam Pelaksanaan Oral Hygiene Pada Pasien Stroke Di Ruang Wijaya Kusumah RSUD Kota Bekasi. Skripsi, Program Studi Ilmu Keperawatan Fakultas
Keperawatan dan Kesehatan Universitas Muhammadiyah Semarang.

Nidyawati, N., Wicaksono, D. A., \& Soewantoro, J. S. 2013. Gambaran Tingkat Pengetahuan dan Kebersihan Mulut pada Masyarakat Lanjut Usia di Kelurahan Rurukan Kecamatan Tomohon Timur. Jurnal Biomedik, 5(1).

Notoatmodjo, S. 2007. Promosi Kesehatan dan Ilmu Perilaku. Jakarta Rineka Cipta.

Notoadmodjo, Soekidjo. 2007. Kesehatan Masyarakat: Ilmu dan Seni. Jakarta: Rieneka Cipta. 
Perry \& Potter. 2005. Buku Ajar Fundamental Keperawatan. Edisi 4 Volume 2. Jakarta: EGC.

Wulandari. 2015. Hubungan Sikap Caring Perawat terhadap Pelaksanaan Oral
Hygiene di Ruang Intensive RSUD Dr. Moewardi Surakarta. Jurnal Program Studi S-1 Keperawatan Stikes Kusuma Husada Surakarta. 